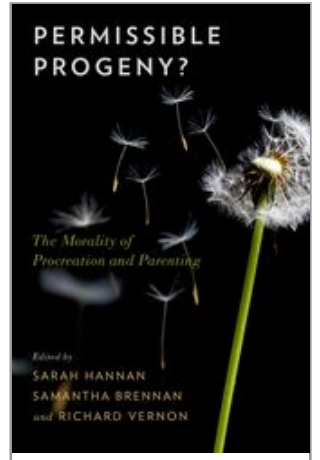

Permissible Progeny?: The Morality of Procreation and Parenting

Sarah Hannan, Samantha Brennan, and Richard Vernon

Print publication date: 2015

Print ISBN-13: 9780199378111

Published to Oxford Scholarship Online: September 2015

DOI: 10.1093/acprof:oso/9780199378111.001.0001

\title{
Could There Ever Be a Duty to Have Children?
}

Anca Gheaus

DOI:10.1093/acprof:oso/9780199378111.003.0004

\begin{abstract}
Keywords
This chapter argues that there is a collective responsibility to have enough children in order to ensure that people will not, in the future, suffer great harm due to depopulation. Moreover, if people stopped having children voluntarily, it could be legitimate for states to incentivize and maybe even coerce individuals to bear and rear children. Various arguments against the enforceability of an individual duty to bear and rear children are examined. Coercing people to have children would come at significant moral cost; however, none of the arguments against enforceability seem decisive. The existence of a collective responsibility to have children bears on the question of whether parents and non-parents ought to shoulder the costs of childbearing and child rearing together.
\end{abstract}

Keywords: childbearing, child rearing, duty, children, depopulation, harm, enforceability, costs, parents, non-parents

\section{Introduction}

Could there ever be a duty to have children? I explore the case for a positive answer and advance the suggestion that there is a collective responsibility ${ }^{1}$ to procreate and raise (enough) children-in short "to have children"-in order to avoid great harm to a potential last generation of childless people. By collective responsibility I mean the duty owed by a group of people to individuals who are vulnerable to how the respective group of people act (or fail to act) collectively. ${ }^{2}$ I also address the question whether such a responsibility can, under certain circumstances, translate into individual and enforceable duties. My interest is not in the related discussion about whether there are reasons to bring into existence children whose lives are very likely to be good, and about the weight 
of these reasons. Rather, I consider the possibility that a general duty to help others can, under certain circumstances, entail a duty to have children in order to avoid dramatic depopulation and its material and psychological consequences on the last generations. If it exists, such a duty would be grounded in the interests of already existing persons rather than in the interests of the prospective children. Therefore, I avoid the contentious assumption that a state of affairs can be better even if it is not better for any person; my line of reasoning is compatible with a person-affecting view of ethics.

(p.88) I consider the possibility of a collective responsibility to have children and the conditions under which it could generate in a pro tanto individual duty only given certain assumptions. First, that the prospective children will have adequate lives ${ }^{3}$ which are not worse, on average, than those of their parents' generation. ${ }^{4}$ Second, that procreation is not, in general, morally wrong. Thus, I start from the background common-sensical view that having children is morally permissible: under normal conditions (including normal demographic and environmental conditions), most individuals ${ }^{5}$ have a liberty right, but no duty, to have children.

Even qualified, the idea that people may ever have a duty to have children is unpopular in secular, liberal, and cosmopolitan circles. We are used to hear from religious and nationalist leaders that people have a duty to procreate in order to accomplish the plans of a deity or in order to contribute to a strong, resourceful nation. Communitarians may argue that the value of particular traditions and ways of living can provide weighty moral reasons for members of the respective communities to have children. But these claims do not sit well with a liberal view that respects individuals' autonomy. Societies worldwide are committed to individuals' freedom to decide whether or not to have children, and how many. This freedom is protected by legal rights encoded in widely endorsed-if not always binding-international conventions. ${ }^{6}$ Not only is there no legal duty to have children, but philosophers discussing the matter generally believe that there is no such enforceable moral duty either. ${ }^{7}$ Christine Overall, for instance, thinks that "[P]eople's rights to control their reproductive functions 'militate against any supposed duty or obligation to reproduce in any way" 8 where she takes "militate against'" to mean something like "rules out." Like many others who hold liberal convictions about autonomy and bodily integrity, Overall thinks there cannot be an enforceable duty to have children because this would come into conflict with those convictions. Finally, there are philosophers who endorse a more fundamental reason against a possible duty to have children. According to David Benatar, it is always morally wrong to procreate-which rules out the possibility of a duty to have children. ${ }^{9}$

Not only is the idea of a duty to have children unpopular amongst liberals, but it also seems out of sync with our times. The context in which I discuss a possible duty to have children is that of a world facing the risk of dramatic depopulation 
due to a lack of interest of people in having children. But, worldwide, we currently fear overpopulation rather than depopulation; philosophical work on procreation and parenting starts to reflect this fact. It is far from clear that the natural environment can sustain the current population growth, at least at existing levels of consumption. (p.89) True, in some countries fertility has been declining, and birth rates are below the replacement level. But these tend to be countries with some of the highest consumption levels (and therefore a population decrease is in this case good environmental news), and undesirable population deficits in these countries can be avoided by means that do not increase the overall population of the world-such as international adoption or migration. Therefore it is not clear that we-especially in highly consumerist societies-have a liberty right to procreate, or to procreate unrestrictedly, since overpopulation is likely to put future generations as well as our contemporaries who live in geographically disadvantaged locations at the risk of great harms. If it is doubtful that there is a right to unrestricted procreation under current circumstances, what is the point of reflecting on a duty to procreate?

Third, there is a pressing egalitarian worry that thinking about a duty to have children-which includes procreation-neglects the interests of existing children in need of parenting. Even without the risk or reality of overpopulation putting into question the morality of procreation, the large number of existing children without parents is enough to make one turn one's attention away from a possible duty to have children. Perhaps we should think, instead, about the duty to look after the children who already exist and are in need of adequate parenting-and, indeed, some philosophers argue that there is a duty to adopt rather than procreate. $^{10}$

Finally, it may seem otiose to enquire into a possible duty to have children: it seems useless to theorize a duty to procreate and rear children, given people's widespread desire to do it anyway. Why use the bigger hammer of moral reasons if the friendly touch of inclination can do the job alone? To sum up, liberal egalitarianism provides several good reasons to resist the idea that there is a duty to procreate.

What Difference Does a Collective Responsibility to Have Children Make? I nevertheless raise this question because a moral requirement to have children will make a significant difference in how liberal egalitarians should think about parenthood. The motivation that drives my enquiry comes from outside the area of reproductive ethics, from its close neighbor, child-rearing ethics. Here, one of the fundamental issues is who should shoulder the significant-and ever mounting!- costs of child rearing ${ }^{11}$ : parents alone, or parents and non-parents together? And, if the latter, how should the costs be split between these two social groups? 
(p.90) I will not take the time to recapitulate this complex debate in detail, ${ }^{12}$ but merely indicate the main positions within the liberal egalitarian discussion. Following Serena Olsaretti, ${ }^{13}$ I call the view that child-rearing costs should be shared by parents and non-parents "the pro-sharing view," and the opposite view "the anti-sharing view." Various liberal egalitarians argue that, in an ideally just world, the costs of child rearing should be borne by their parents, on two different grounds: First, because parents are causally and morally responsible for the existence of children, assuming that procreation is informed and intentional. (This may not be true of all or even the majority of real-world parents, but the discussion is set at the ideal level.) Child rearing is costly, and it would be unfair to impose the costs on non-parents, who have no say about children's existence in the first place. Second, because having children is a lifestyle that some people value while others-including the voluntary nonparents-do not; child rearing is to be understood by analogy with expensive tastes, or perhaps with creating something valuable, like a beautiful painting. Since neither the satisfaction of expensive tastes, nor the funding of creative pursuits in general are required by justice, it is only fair that the costs of child rearing be taken by those who also enjoy the benefits of child rearing: parents.

However, it seems clear that not only parents enjoy the benefits of children's existence. Some of the defenders of the pro-sharing view note that, by having children and raising them well, parents make an important contribution to future public and collective goods. In a few decades, the argument goes, today's adults will have to rely on today's children for their welfare; the sustainability of a pension system, which requires new workers, is the example given most often. ${ }^{14}$ The view that children are sources of public and collective goods entails, according to some defenders of the pro-sharing view, that it is unfair that parents alone should carry the costs of bringing up children.

The public and collective goods argument has so far failed to convince the proponents of the anti-sharing view. ${ }^{15}$ They note that people do not have children with the intention of benefiting others, nor do they see their having and rearing children as some kind of cooperative venture in which parents and nonparents engage together, but rather as a private enterprise from which nonparents merely happen to benefit. In arguing that there is a collective responsibility to have children, I intend to challenge the last type of defense of the anti-sharing view.

An important question, then, is how the members of a community ought to see the cooperative aspect of child rearing, rather than how they in fact see it.

Suppose that non-parents should have a say about whether there will be a future generation although they are not willing to contribute by procreating (p.91) or by doing the hands-on work necessary to raise that generation themselves. Then non-parents are likely to have a duty of fair play to contribute financially to the effort of raising an optimal number of members of that generation. If there is a 
collective responsibility to have children in order to avoid future harm to both current parents and non-parents, then having children-up to the number that is required to meet the responsibility-is in fact a cooperative enterprise between parents and non-parents. In this case, it is plausible that individuals who volunteer to parent and thus meet the collective responsibility are owed financial support from those who do not want to take part directly in meeting the responsibility. True, parents are not likely to be motivated to parent by a desire to discharge a collective responsibility (and they may not see their parenting primarily_or at all—as an activity aimed at meeting a collective responsibility). Contributing to a public good is not their primary intention in raising children. Yet, in this context, intentions alone do not seem to make a difference. Consider the analogy, often used to help us think about the social nature of the burdens of child rearing, between going to war and having children: I may enroll in an army of volunteers because I want to partake in the glory of war rather than to do my duty in defending my people. I will not, for this reason, be expected to fund alone my participation in the army; rather, fairness seems to require that I be given the goods necessary for subsistence during service, possibly a salary, and medical care resulting from injuries during service. That I am motivated by an intention to acquire glory rather than live up to my responsibility does not take away from the fact that the people I defend have a duty to help defray the costs of my enrollment in the army.

In fact, if there is a collective responsibility to have children, the foundation of the anti-sharing view is shaken: in this case having children is not akin to either an expensive taste or to the creation of something valuable but morally supererogatory. Nor is the fact that procreation is intentional and informed relevant for the question of who should pay the costs of childbearing and child rearing, up to an optimal population size. Even if current parents did not want to have children, either they or others ought to have some of them. One way or another, the costs of having children should not be collectively avoided.

\section{A Collective Responsibility?}

But is there such a responsibility? Consider the following story: the inhabitants of a certain state have always depended on a complex system of welling for water; everybody has a well in their garden, and a system of (p.92) cleaning the water to make it drinkable is maintained through some form of spontaneous social cooperation. A number of individuals voluntarily work in well digging and water well maintenance, support the costs of providing everyone with clean water and are fairly rewarded for their work. But at some point in time no new people are interested in working as well diggers or in water well maintenance. Unless collective action is taken, the reserves of clean water will start to dry out. Without enough people being trained and convinced to maintain the supply, there will be increasing shortages of clean water and, in twenty years' time, 
everybody will die of thirst. Suppose that some of the people who will suffer are, at the present moment, still children.

Do the members of this state have a collective responsibility to ensure that those of them who will still be around in twenty years will continue to be provided with clean water? And, if so, ought the state authorities adopt policies that nudge some individuals to work as water providers? Should nudging fail, ought the state to adopt more coercive policies that result in new people taking up this essential kind of work? More generally, do we have a collective responsibility to ensure that goods and services essential to the satisfaction of basic needs are being socially produced? And, if market mechanisms fail to result in their production, ought states to meet the collective responsibility through policies that translate it into individual, and possibly enforceable, duties?

The most promising ground for a positive answer is to point to a general dutybe it of justice or of beneficence-to avoid the frustration of basic needs. ${ }^{16}$ More specifically, if some persons are vulnerable for the satisfaction of their basic needs to the way in which others, taken as a group, act or fail to act, the latter bear collective responsibility for the first. ${ }^{17}$ People need clean water if they are not to die prematurely, and if they are not to suffer unnecessarily. It is plausible that, if nobody wanted to work towards the provision of clean water, the state authorities ought to either provide special incentives to some to engage in this kind of work, or, failing that, to find the least problematic means of coercing individuals to cooperate in ensuring a sufficient supply of drinkable water. (For simplicity, assume the option of bringing guest workers from a different country is unavailable.)

One tempting way to resist the idea that there is a collective responsibility to ensure the future production of clean water is by noting that, in the imagined case, it is not clear that there would be any victims and perpetrators should the alleged duty remain unmet. If citizens failed to organize their own future water supplies, they would only have themselves to blame. Moreover, if they are well informed, perhaps they have the authority to trade the future satisfaction of basic needs for present (p.93) occupational freedom and make an informed, and legitimate, decision to go without water in twenty years. Yet, there are several reasons that support the existence of a collective responsibility in the case of the drying-out threat. Each of these reasons may be enough to dispel the objection; their conjunction makes the case stronger. First, in this imagined case no single individual can ensure a continuous supply of clean water for herself or her own family. Clean water is a type of collective good for the existence of which people cannot be held individually responsible. Second, some of the people who will suffer are now too young to make a responsible and authoritative decision to let their future basic need for water be frustrated. And third, more contentiously, it is not clear that in situations like this even adults have the authority to trade the satisfaction of essential future interests for the 
sake of less important current ones; we know that people are inclined to discount future well-being, at very high rates if the future is sufficiently distant, and that in most cases this is a failure of rationality.

It is even more tempting to resist the idea that, even if a collective responsibility to prevent the frustration of basic needs exists, it can never translate into state policies that coerce (some) individuals into particular jobs. Many liberal egalitarians believe that individuals have a freedom-right to occupational choice, and that it is unjust for states to take coercive measures aimed at ensuring that particular jobs get done, even when these measures are necessary for reaching equality, or an adequate minimum, or an improvement in the situation of the worst-off. ${ }^{18}$ While I do not have the space to discuss this important issue here, let me only mention three reasons why appeal to freedom of occupational choice does not make the present enquiry a non-starter. First, it is unclear that freedom of occupational choice is consistent with an adequate liberal egalitarian theory of justice. ${ }^{19}$ Second, in spite of the widespread view that justice is the first virtue of a society, it is not implausible to think that moral considerations other than justice can sometimes trump requirements of justice; a duty of humanity to prevent extreme and generalised suffering is likely to be such a consideration. In fact, many states do infringe on their citizens' freedom of occupational choice if this is needed to secure the avoidance of great harm, for instance in the context of providing health care. Over seventy countries have used compulsory service programs in recent times to recruit health workers for the provision of essential health care services in deprived areas. ${ }^{20}$ Third, and related to the previous point, it is not obvious that the situation under consideration-a society that is at risk of breaking down due to lack of basic resources-meets the conditions that some philosophers consider necessary in order for concerns of justice to arise in (p. 94) the first place. Rawls has famously, and controversially, argued that justice is a virtue of societies where certain conditions or "circumstances of justice" hold, and one of these is moderate, rather than extreme, scarcity of resources. But a world without drinking water, or with an economy on the brink of massive breakdown, looks more like one in which resources are extremely scarce and which therefore is not characterized the usual "circumstances of justice." So states may be justified in adopting coercive policies that would be unjust under normal conditions, if this is what it takes to avoid a situation in which considerations of justice would become obsolete.

There is a close analogy, for the purpose of this chapter, between having children and working to create future water supplies as in the example-only that children make possible a larger number of public and collective goods. The benefits that everybody, including people who do not want to raise children, enjoy as a result of there being children are hard to overestimate. Some of them are indeed material, but not restricted to pensions, while others are not 
material, and possibly just as important. To see this, consider what it would mean if everybody stopped having children.

One consequence would be immense physical suffering for many members of the last generation. A new generation is needed in order to avoid people dying from unnecessarily painful and probably premature deaths. Without a new generation, the economy would collapse. It is unavoidable that many people end their lives in a state of dependency (the old, the ill, the disabled) and if there was no one to care for them they would die hungry, thirsty, and without pain relief and other palliative care. Not only services, but also material goods would become extremely scarce if everybody stopped having children. A working pension system is a good made possible by rearing children, but a focus on pensions alone is too narrow. Some people-who are independently wealthy, or who save enough—can survive without pensions. But they cannot survive without a minimally working economy, and most people cannot do without some hands-on care during times of temporary illness. Therefore, taking a wide view of the economic benefits of rearing children can show that having a working economy itself is a cooperative venture not only between contemporaries, but also diachronically between generations-and hence, indirectly, between parents and non-parents.

More contentiously perhaps, all of us-old and young, parents and non-parentsdepend psychologically on the existence of future people: our motivation to accomplish things, and probably even our zest for life, are possible because we take for granted the existence of future generations. We need to believe in their existence if all, or almost all of our activities (p.95) are to have meaning and if we are to avoid a state of perpetual apathy and gloom. At least this is what Samuel Scheffler-drawing on others-has recently argued. ${ }^{21}$ If he is half right, then future generations-or rather their parents-benefit us by providing the background, inconspicuous, motivational conditions for life as we know it.

Even more contentiously, one may think that there is a collective responsibility to have sufficient children in order to ensure the continuation of political society. This line of reasoning can be found, in nuce, in Rawls who wrote that: "[P]olitical society is always regarded as a scheme of social cooperation over time indefinitely; the idea of a future time when its affairs are to be concluded and society disbanded is foreign to the conception of political society. Thus, reproductive labor is socially necessary labor." ${ }^{22}$ One aspect of the undesirable consequence of an entire citizenry stopping to have children is impersonal: the disappearance of the political society, which may be as such regrettable. But there is also a person-affecting aspect of the disappearance of the political society: the last people to be alive will be deprived of the good of living in an institutionally organized society that can regulate and legitimize the uses of power. 
There is a collective responsibility to avoid all these bads. Of course, the responsibility is not merely to bring into existence sufficient children in order to make all these present and future goods possible. The responsibility goes well beyond a duty to procreate, to include a duty to raise a new generation of individuals who, at the very least, are ready to cooperate in order to prevent the avoidable frustration of basic needs.

\section{Enforceability}

The next question, to which I now turn, is whether a duty to have children can ever be enforceable. Ought state authorities to incentivize or even coerce people to have children, if too many people stopped doing so voluntarily? A positive answer is more likely than a negative one to shed some light on the sharing of the costs of child rearing under present circumstances. If a collective responsibility to have children can generate enforceable duties, it is hard to see how some may legitimately opt out of supporting those who discharge it on their behalf. ${ }^{23}$ If, by contrast, the duty is not enforceable, then perhaps people should be allowed to opt out just like they are granted other "rights to do wrong." 24

The claim that there is an enforceable duty to have children will confront immense theoretical obstacles stemming from widespread beliefs about autonomy and good parenting. Even if one disagrees that individuals (p.96) always have a freedom-right to occupational choice, one may think that procreation and child rearing are kinds of activities that should never be coerced or even actively promoted through state policies. I shall look at those reasons I find most compelling in favor of this position, and suggest some tentative answers.

I shall consider, in turn, adults-centred and children-centred arguments against the idea that states may ever promote or enforce a duty to have children. The first set of arguments has to do with the importance of the potential parents' autonomy and with their rights in their own bodies. Separate concerns will be discussed with respect to procreation and child rearing. The second set of arguments is about the potential children: would they be impermissibly used as means rather than ends in themselves, and would they necessarily be deprived of adequate parenting, if raised by people who have not chosen parenthood voluntarily?

Some of the reasons against enforceability are more powerful than others, and I am not sure they can all be satisfactorily met but, at the very least, they are not as compelling as usually assumed.

\section{Adults}

One objection to an enforceable duty to have children is that there cannot be a duty to have children because both procreation and child rearing are highly intimate activities. A plausible system of enforceable duties cannot regulate the most intimate aspects of human beings with burdening positive duties because 
this would jeopardize autonomy. The thought here is that the most intimate aspects of our lives are closely connected to our moral and rational agency; thus, to protect our agency-including moral agency-we need a significant degree of freedom when deciding how to act with respect to these aspects of our lives. ${ }^{25} \mathrm{I}$ will not question here the truth of this general principle, nor resist the liberal endorsement of the value of autonomy. I assume that the important issues are (1) whether an enforceable duty to have children is compatible with personal autonomy under any circumstances, and (2) whether values other than individual autonomy, such as for instance an egalitarian commitment to avoid the frustration of basic needs, can have sufficient weight to generate the enforceability of the duty under consideration even when enforcing that duty is inimical to autonomy.

I disentangle the two separate questions of whether, and to what extent, autonomy is compromised by a duty to have children. First, would the enforcement of a duty to procreate necessarily be a serious infringement on (p. 97) autonomy? And second, would the enforcement of a duty to rear children necessarily be a serious infringement on autonomy?

It is not uncommon to believe that people have duties to help others that involve the use of their body and bodily parts. We think that sometimes we owe others personal services and many think that people have a moral duty to donate body parts-most often blood. The really contentious issue is whether such duties can ever be enforceable. It is quite obvious that an enforceable duty to procreate does not sit well with respect to individual autonomy, as long as gestation is necessary for procreation. Pregnancy is a long-term, labor- and emotionintensive experience. ${ }^{26}$ It comes with health risks-which are sometimes significant-and it often involves discomfort and pain. Giving birth naturally can also be painful, even extremely so, even if painkillers are used, and caesareans are a type of major surgery. And we know that women perceive forced pregnancy as extraordinarily intrusive. In short, coerced pregnancy is incompatible with respect for autonomy; moreover, the violation of autonomy in this case is so serious that it is difficult to see how it could be outweighted by other moral considerations. This means that, at most, states can legitimately create certain incentives for individuals to bear children-making sure they do not make pregnancy the only acceptable choice for any particular individual.

However, technological development may render pregnancy optional for procreation. If and when this happens, the most formidable autonomy-based argument against an enforceable duty to procreate will disappear. The use of people's bodies will still be necessary for procreation, but a much more modest level of interference will be required. Gamete donation is not the most trivial medical procedure, but perhaps it will become possible to create artificial gametes using skin. Unlike in the case of pregnancy, it is less clear that a one-off requirement that individuals serve as gamete or skin donors necessarily 
infringes on their autonomy. Or, if some autonomy infringement is involved, this appears to be an acceptable price to pay for making possible a new generation.

Separate from how the process of gamete donation may infringe on autonomy, there is the question of whether individuals own their gametes, and therefore nonconsensual gamete extraction amounts to theft. An enforceable duty to procreate is incompatible with an unqualified right to bodily self-ownership. But egalitarianism (with the possible exception of left-libertarian egalitarianism) seems to rule out an unqualified right to either personal integrity or bodily selfownership. Cecile Fabre argued that a consistent egalitarian theory of justice should recognize that the worse-off have rights to other people's personal services and bodily organs, (p.98) if these are necessary to meet their needs. ${ }^{27}$ (Moreover, she argued that respect for these rights is compatible with respecting a qualified right to personal integrity and to autonomy.)

Like childbearing, child rearing can limit parental autonomy. It is a very intimate, emotionally intense, labour- and time-demanding commitment. Because one of children's most important needs is continuity in the relationship with their parents, parenting is also a particularly long-term endeavour, one which has no or very difficult exit options. Indeed, the combination of all these features led Anne Alstott to argue that (proper) parenting entails a very significant diminution of parents' autonomy, one for which parents are being owed some compensation. ${ }^{28}$ But, of course, exactly how intensive and resource demanding child rearing is depends a lot on how it is socially organized. Parenting a particular child could be more socialised than it is currently in societies where nuclear families are dominant. Studies indicate that spending significant time in child-rearing institutions such as day care and kindergartens is not necessarily detrimental to children's well-being. ${ }^{29}$ If the hands-on aspect of child rearing was partly socialized-by putting in place adequate child-rearing institutions and/or other communal ways of bringing up children-rearing a child would be a lot less inimical to parents' autonomy than the current status quo in many Western societies. Moreover, to the extent to which child rearing takes place in the family it need not be the job of only one or two individuals. Currently, several societies are moving towards a practice of sharing child rearing between more than two related adults; having a larger number of parents-say three or four-need not be detrimental to children's well-being, nor to other central values of the family such as intimacy and love. ${ }^{30}$ Child care could be reorganised such that it conflicts with parents' autonomy to a much lesser extent than it currently does.

However, no matter to what extent we were to socially reorganize child care, the sacrifice in parental autonomy would be considerable, especially if children's need for continuity in care is to be met. I don't know whether this means that a duty to rear children can never be enforceable. Accepting this conclusion would also mean to accept that, should a society's children tragically lose their parents, 
and should the remaining adults be unwilling to parent, these adults could not be legitimately coerced into parenting the orphans. I find this implication implausible. At the very least, it seems, the orphans' needs would generate an enforceable duty for the adults to organize decent child-rearing institutions and divide the child-rearing work between themselves in a way that ensures that children's needs are met (including the need for continuity of care, if it is as important as developmental psychology suggests it is). In the orphans' (p.99) case-as well as in the real-life case of orphaned children-it seems that states may and should provide incentives for adoption and, if that fails, incentives for low staff turnover in full-time institutional care.

To conclude this section, enforcing a duty to procreate would entail a massive infringement of autonomy by imposing childbearing. If, however, childbearing was to become obsolete, an enforceable duty to procreate would not raise major worries concerning the gamete donors' autonomy. In contrast, enforcing a duty to rear children is likely to unavoidably entail some loss of autonomy; yet, in other situations-such as the orphans' example-we are likely to judge such an infringement of autonomy as legitimate, if it is the only way to meet the children's basic needs. If the meeting of some people's basic needs justifies the infringement of autonomy in the case of the orphans, why would the meeting of other people's basic needs not justify the infringement of autonomy in the case of imminent depopulation?

\section{Children}

A second group of worries concerns the potential children who would be born as a result of states encouraging, or possibly coercing, individuals to have children: would these children be thereby subjected to impermissible treatment? ${ }^{31}$

Before addressing these worries, let me reiterate the assumption that a duty to have children is explicitly constrained by adults' ability to give the prospective children a good chance to lead acceptably good lives. This means that, for instance, in a world afflicted by natural disasters, extreme shortage of resources, or endless wars, we would have no duty to procreate and rear children in order to alleviate future suffering (and possibly no right to procreate for any other reason).

Even so, the creation of children with the intention to meet other people's basic needs has been thought to be morally wrong, as the discussion of savior siblings shows. Savior siblings are children born as a result of their parents selecting, from several zygotes, the ones that will result in a child who can provide an organ or cell transplant to a sibling that is affected with a fatal disease. The creation of savior siblings has been criticized for treating the prospective children as mere means to an end. As several authors pointed out, this criticism is unconvincing. ${ }^{32}$ Savior siblings are not treated as mere means, if, once they 
exist, they are also cherished for themselves, loved by their parents, and given the same respect and care due to all human beings.

(p.100) There is, however, a significant difference between savior siblings and the prospective children discussed here-a difference which may, but need not, make the mere means charge more difficult to address. Savior siblings are raised by parents who are willing to have that particular child, not by people who see themselves as acting on duty, much less people who are acting under an enforced duty. As far as respect and being treated justly are concerned, it need not make a difference whether or not children are raised by people nudged or coerced into parenting. However, things may be different with respect to love and emotional attachment between parents and children. If love and attachment are very difficult to achieve unless parenting is freely chosen, there are two grounds on which one should resist the enforcement of a duty to have children. First, because it would lead to the existence of children who are unwanted for themselves, and hence more likely to be treated as mere means to an end. Second, because it is possible that a serious failure of emotional attachment between parents and children is incompatible with ensuring an adequate life for the child.

Therefore, a lot depends on what is parental love and under what conditions it is likely to develop. Do most people really need to voluntarily assume the rearing of a child in order to form a deep and committed emotional bond with them? Some may think that good parenthood must be both non-moralized (that is, not done out of duty) and freely chosen (that is, not done out of a promoted or enforced duty). In this case, the charge of using the unwanted children as mere means, and of letting them be harmed, is more credible.

Or, by contrast, will most people spontaneously and unavoidably bond with children whom they see as their responsibility to rear? The latter situation is not implausible: as parents look after their children, children respond emotionally to their parents, and for most people this may be enough to create the initial bond. It is likely that most children have not been brought into the world intentionally, at least until recently; yet, we do not tend to worry that parents who had their children thrust upon them by chance failed, for this reason, to love them. ${ }^{33}$

\section{Some Tentative Conclusions}

The question raised here is whether, given liberal egalitarian assumptions, individuals can ever have a duty to have children-that is, to procreate and rear children. A subsequent question is whether, in case there is such a duty, states can be justified in policy-making to induce individuals to satisfy the duty or even to coerce them to do so.

(p.101) I assumed that there is a duty to prevent basic needs from being frustrated, that basic needs will be frustrated if everybody stopped having children, and that making possible a new generation requires collective action. 
Since cooperation is necessary to avoid the harms of being the last people, the state is responsible to take action to see that harm be averted. The only way to bring about a new generation is to have people procreate and rear children. I suggested that, just like a state whose citizens are at high risk of running out of clean water has a duty to encourage citizens to become water-providers, a state whose citizens stop procreating has a duty to encourage procreation. But can states ever be justified in nudging or even conscripting their citizens into procreation and child rearing?

The reason for asking if there can be a duty to have children is that the answer bears on the fair way of sharing some of the costs of childbearing and child rearing between parents and non-parents. To provide a powerful argument in favor of the pro-sharing view, it is not enough to show that each generation has a duty to have up to a (certain number of) children; the duty should be such that individuals cannot claim state protection for a freedom to act against it. When individuals claim a right to do wrong, they claim a freedom from interference with doing what they have a moral duty not to do, or with not doing what they have a moral duty to do. Many are puzzled by the thought that people can have rights to do wrong and there are several ways of making sense of such rights; I find most plausible the understanding that there is a right to do wrong only when there are no legitimate ways of interfering with individuals' failing to do their duty. It follows that an adequate discussion of the enforceability of a duty to have children would need to examine the legitimacy of particular possible pronatalist policies. This is an issue I did not attempt to discuss here; instead, I pointed out which policies are very unlikely to be ever legitimate, such as coerced pregnancy. The most convincing argument against the possibility of an enforceable duty to have children-that forced pregnancy seriously violates women's autonomy-could in theory be made obsolete by technological development. I have also attempted to dispel the worry that consideration of adult autonomy and child welfare make all pro-natalist policies in principle illegitimate.

The existence of a collective responsibility to have children in order to prevent great harm has consequences for other issues. Most immediately, it bears on the question of whether there is not merely a right, but also a duty to bring into the world "savior children" if this is necessary for the satisfaction of the basic medical needs on an existing individual. I started this chapter by suggesting that a collective duty to have children can help us think about the question of who should shoulder the burdens of child (p.102) rearing. It is to that question that I now return. What, if any, difference does a collective responsibility to have enough children make to how we should decide who should pay for children? In the world as it currently is people volunteer to have enough-or more than enough-children and therefore live up to the collective responsibility without much incentive, let alone coercion. However, the existence of a collective responsibility to have enough children indicates one reason why it is inadequate 
to model child rearing (up to an optimum population) as a form of expensive taste or a hobby. If volunteering to have children is more like volunteering to defend your community against aggression than like indulging in fine wines or producing beautiful sculptures in your spare time, then there is a stronger case that having children is a form of social cooperation. And if having children is a form of cooperation, then fairness requires that some of its costs be socially shared. The interesting question, then, is which of the costs of childbearing and child rearing should be socialized. A plausible suggestion is that we should socialize, on grounds of fairness, the morally mandatory costs of childbearing and child rearing, up to an optimum number of children. These are likely to include the costs of providing children with proper nutrition, clothing, homes, safety, health care, education, and non-overworked parents, but are not identical with the full costs of child rearing. Parents also tend to spend money for goods that are not necessary to ensure an adequate level of well-being to their children. ${ }^{34}$

However, to capture the spirit of the anti-sharing view, it is essential to note that rearing children represents, for most people, a benefit as well as a source of financial and non-financial burden, and this seems crucial for determining what is a fair distribution of the costs of child rearing between parents and nonparents. If there is no shortage of children this is precisely because parenting is so valuable to many people that they are keen on having children, in spite of the significant (non-shared part of the) cost of raising them in developed countries. The next questions, then, are whether and how the intrinsic valuing of parenting should be factored in determining what fairness demands in terms of sharing the costs of having children. Whatever the correct answers to these questions, it is highly unlikely that they will entail that parents should shoulder alone the morally mandatory costs of childbearing and child rearing. Remember the analogy with ensuring an adequate water supply; before the threat of shortage, people were organizing the provision of water through voluntary cooperation, without the intervention of the state. This is the right analogy for a situation in which enough people volunteer to have children. (p.103) The task is to determine what is the fair amount of support, if any, that they should be socially given for rearing children. In the imagined story, the exact form of cooperation was intentionally left unspecified: perhaps it was through a free market exchange, perhaps it was a more communal way of organization, such as a services co-op. Similarly, the motivation of the workers supplying water was left unspecified: perhaps supplying water was, for them, a mere job, or perhaps it was (also) done from a sense of pride in providing an essential good to their community. Even if we imagine that the water was provided via market mechanisms, and free market exchanges should determine the level of fair compensation, and even if we imagine that workers were motivated by pride, such that they were ready to do their work without pay, it would be highly implausible to think that fair compensation for providing water could be less 
than the costs of production. Indeed, a case in which some people provide an essential good to their community and support the costs of production themselves without getting any compensation looks a lot more like exploitation than like a fair market exchange. If such a practice was ongoing on any significant scale-if, say, some people voluntarily supplied clean water, supporting themselves the costs of production and without any financial compensation from their community-we would rightly suspect that the water suppliers are exploited. We would suspect that something in their motivational dispositions, or perhaps a structural aspect of their relationship with the rest of the citizens makes them vulnerable to an obviously unbalanced social exchange.

Similarly, assume that the fair level of financial support that non-parents owe to parents should be sensitive to the level of incentive that some people demand in order to parent, and that people in fact need very low incentives in order to parent: they value parenting enough to happily put in all the time, effort, and foreclosed opportunities without compensation. If indeed having (enough) children is a matter of social responsibility, then it is very implausible to think that fairness will demand from non-parents to share with parents less than the morally mandatory costs of childbearing and child rearing. It is perhaps not impossible to imagine that some individuals would want to have children even if they had to support themselves all the costs of bearing and rearing them-in terms of money, time and effort-without any societal help. But the most plausible explanation of why they would want to do this is that the desire to have children is so overpowering and hence unresponsive to reasonable assessment that it makes individuals who have it vulnerable to exploitation. ${ }^{35}$

Notes:

(1.) In this chapter I take "duty" and "responsibility" to be the same thing. I use the first to refer to individual duties and the second to refer to collective ones.

(2.) See Robert Goodin, Protecting the Vulnerable. A Reanalysis of Our Social Responsibilities (Chicago: Chicago University Press, 1985).

(3.) I intentionally avoid the discussion of the threshold of well-being of a prospective person below which it is plausible that bringing that person into existence is impermissible. At least, the threshold is at the level where the life is worth living - that is, the well-being of the life offsets its badness.

(4.) And so I avoid, as well, the question of which principle of distributive justice should regulate relationships between successive generations-that is, whether parents owe their children equality or sufficiency.

(5.) Because "having children" includes, for the purposes of this chapter both procreation and child rearing, I assume that only those individuals who would make adequate child rearers have this right. 
(6.) Reproductive rights figure as a subset of human rights since the 1968 Proclamation of Tehran, which stipulates that "Parents have a basic right to decide freely and responsibly on the number and spacing of their children and a right to adequate education and information in this respect." The same right is reiterated by the Cairo Programme of Action, a document adopted in 1994 recommending that governments prioritize the respect of individuals' reproductive freedoms over demographic targets.

(7.) For an exception, see Saul Smilansky, "Is There a Moral Obligation to Have Children?" Journal of Applied Philosophy 12, no. 1 (1995), 41-53.

(8.) Christine Overall, Why Have Children? The Ethical Debate (Cambridge, MA: MIT Press, 2012), 76.

(9.) David Benatar, Better Never to Have Been: The Harm of Coming Into Existence (Oxford: Oxford University Press, 2006).

(10.) See Daniel Friedrich, "A Duty to Adopt?” Journal of Applied Philosophy 30, no. 1 (2013): 25-39; and Tina Rulli, "The Unique Value of Adoption," in FamilyMaking: Contemporary Ethical Challenges, ed. Francoise Baylis and Carolyn McLeod (Oxford: Oxford University Press, 2014).

(11.) Strictly speaking, the argument here bears both on the costs of child rearing and on the costs of childbearing. But since the former are much greater, and since they-rather than the costs of childbearing-are the object of a heated dispute concerning who should shoulder them, I often refer only to "the costs of child rearing."

(12.) Good summaries can be found in Serena Olsaretti, "Children as Public Goods?" Philosophy and Public Affairs 41, no. 3 (2013): 226-258, and Patrick Tomlin, "Should Kids Pay Their Own Way?" Political Studies. DOI: 10.1111/1467-9248.12111, 2014 (forthcoming).

(13.) Olsaretti, "Children."

(14.) The best-known proponent of this argument is Nancy Folbre; for instance, “Children as Public Goods," The American Economic Review 84, no. 1 (1994): 86-90.

(15.) Paula Casal, "Environmentalism, Procreation, and the Principle of Fairness," Public Affairs Quarterly 13 (1999); Paula Casal and Andrew Williams, "Equality of Resources and Procreative Justice," Dworkin and His Critics, ed. Justine Burley (Oxford: Blackwell, 2004).

(16.) I take basic needs to be especially powerful interests. They include, uncontroversially, needs for clean water and other things necessary for physical 
survival, as well as relief from physical pain. I see no reason why they would not also include relief from intense psychological suffering.

(17.) According to Goodin, Protecting the Vulnerable.

(18.) John Rawls, for instance. See the discussion in Lucas Stanczyc, "Productive Justice," Philosophy and Public Affairs 40, no. 2 (2012): 144-164.

(19.) See Stanczyc, "Productive Justice." For a liberal egalitarian theory of why states are permitted to require that citizens provide personal services and even body parts, see Cecile Fabre, Whose Body Is It Anyway? Justice and the Integrity of the Person (Oxford: Oxford University Press, 2006).

(20.) Seble Frehywot, Fitzhugh Mullan, Perry W. Payne, and Heather Ross, "Compulsory Service Programmes for Recruiting Health Workers in Remote and Rural Areas: Do They Work?" Bulletin of the World Health Organization 88, no. 5 (2010): 364-370.

(21.) Samuel Scheffler, Death and the Afterlife, ed. Niko Kolodny (Oxford: Oxford University Press, 2013).

(22.) John Rawls, “Idea of Public Reason Revisited," in The Law of Peoples, with "The Idea of Public Reason" Revisited (Cambridge, MA: Harvard University Press, 1999), 157.

(23.) At least if one accepts the principle of fair play. One of its best-known defenders, George Klosko, sees the principle of fair play as restricted to goods that "can be presumed to be necessary for an acceptable life." In the previous section, I showed that children are necessary for a bearable life. See George Klosko, "Presumptive Benefit, Fairness, and Political Obligation," Philosophy \& Public Affairs 16, no. 3 (1987): 247.

(24.) Liberals tend to agree that certain individual duties should not be enforceable; for instance, people should be free not to donate any money even if they have a duty of charity, and should be free to vote for parties with morally problematic agendas.

(25.) Williams Bernard and J. J. C. Smart, Utilitarianism: For and Against (Cambridge: Cambridge University Press, 1973); Seana Shiffrin, "Moral Autonomy and Agent-Centred Options," Analysis 51, no. 4 (1001): 244-254.

(26.) An excellent, book-length discussion of the philosophical relevance of pregnancy is Amy Mullin's Reconceiving Pregnancy and Childcare: Ethics, Experience, and Reproductive Labor (Cambridge: Cambridge University Press, 2005).

(27.) Fabre, Whose Body. 
(28.) Anne Alstott, No Exit: What Parents Owe Children and What Society Owes Parents (Oxford: Oxford University Press, 2004).

(29.) Jane Waldfogel, What Children Need (Cambridge, MA: Harvard University Press, 2006).

(30.) Daniela Cutas, “On Triparenting: Is Having Three Committed Parents Better Than Having Only Two?” Journal of Medical Ethics 37, no. 12 (2011): 735738. Samantha Brennan and Bill Cameron, "How Many Parents Can a Child Have?” DOI: http://dx.doi.org/10.1017/S0012217314000705

(31.) I leave to one side, for the purpose of this work, the easy solution made available by the non-identity problem: given that the children in question would not exist at all without the state promoting or enforcing a duty to have children, they cannot be said to be harmed by the enforcement of such a duty (unless their lives would be so bad as to be not worth living).

(32.) See, for instance, SallySheldon and Stephen Wilkinson, "Should Selecting Saviour Siblings Be Banned?" Journal of Medical Ethics 30, no. 6 (2004): 533537.

(33.) I am grateful to Lindsey Porter for pointing this out.

(34.) For this distinction between morally mandatory costs of child rearing and costs of child rearing that are not morally mandatory, see Olsaretti, "Children."

(35.) For helpful feedback on previous drafts, I am grateful to Christine Bratu, Lindsey Porter, and the participants in the "Permissible Progeny" conference that took place at Western University in London, Ontario in July 2013. While writing this chapter I have benefited from a De Velling Willis Fellowship at the University of Sheffield. Work towards this article was also supported by the Swedish Research Council, grant no. 421-2013-1306. 